\title{
Efficient Organization of Production: Nested versus Horizontal Outsourcing
}

\author{
Oz Shy and Rune Stenbacka
}

\begin{abstract}
:
The authors characterize equilibrium and efficient modes of production by comparing nested (vertical) outsourcing with horizontal outsourcing. Nested outsourcing is found to be inefficient unless the cost of monitoring outsourced production lines increases sharply with the number of subcontractors and not only with the number of outsourced components. They characterize a market failure in which nested outsourcing is selected when the case dictates that horizontal outsourcing is the efficient outsourcing mode. This failure occurs at an intermediate range of the costs of monitoring outsourcing to several subcontractors.
\end{abstract}

Keywords: outsourcing, subcontracting, nested outsourcing, horizontal outsourcing, efficient organization of outsourcing

JEL Classifications: D2, L2, L24

Oz Shy is an economist in the research department at the Federal Reserve Bank of Boston. His e-mail address is oz.shy@bos.frb.org. Rune Stenbacka is a professor of economics at the Hanken School of Economics in Helsinki. His e-mail address is Rune.Stenbacka@hanken.fi.

This paper, which may be revised, is available on the web site of the Federal Reserve Bank of Boston at http://www.bos.frb.org/economic/wp/index.htm.

We thank Marc Rysman and Scott Schuh for most valuable suggestions and comments on an earlier draft. Rune Stenbacka thanks RUESG, University of Helsinki for financial support.

The views and opinions expressed in this paper are those of the authors and do not necessarily represent those of the Federal Reserve Bank of Boston or the Federal Reserve System. 


\section{Introduction}

The Wall Street Journal (European Edition, December 7-9, 2007) described the repeated delays in launching Boeing's new 787 Dreamliner passenger aircraft in late 2007. According to the Wall Street Journal, the crucial mechanism behind these problems was that Boeing's subcontractors had outsourced the production of some of the components, which formed chains of outsourcing contracts. These outsourcing chains became very complex so that Boeing lost control of its project. The article suggested that the outsourcing performance suffers significantly when the original subcontractors themselves start outsourcing the production of certain components - that is, when they engage in what we will call nested (vertical) outsourcing. ${ }^{1}$ This example essentially illustrates that the structure of outsourcing has a significant effect on the cost of production in industries with high component-specific monitoring costs.

Indeed, the form of outsourcing a firm uses has significant consequences on production in all industries in which component-specific monitoring plays an important role. The design of procurement auctions offers a good example. When designing a public procurement auction the authorities have to decide whether or not to allow for ex-post horizontal outsourcing between competing bidders. This paper constructs a model to characterize the efficient outsourcing structure by comparing nested outsourcing with horizontal outsourcing in industries in which production relies on component-specific monitoring. The model shows that there is a market bias towards nested outsourcing in the sense that there are circumstances under which the market outcome yields an outsourcing mode with nested outsourcing even though horizontal outsourcing is more efficient.

The study of outsourcing is one of the core issues analyzed in organization theory. Important contract-theoretic studies, such as those conducted by Williamson (1985), Grossman and Hart (1986), and Holmström and Roberts (1998), have analyzed outsourcing within the tradition of focusing on the firm's boundaries. During the last decade

\footnotetext{
${ }^{1}$ Business Week (January 16, 2009) suggests that Boeing's experience might call for a return to an increased proportion of in-house production.
} 
the contract-theoretic approach has been complemented with studies presenting perspectives based on industrial organization. The industrial organization approach focuses on firms competing with their production design mode as the main strategic instrument. In an important contribution Grossman and Helpman (2002) analyze the choice between in-house production and outsourcing, linking the firm's equilibrium production mode to industry-specific features such as the efficiency of the search technology, the degree of substitutability between the consumer products, and the relative bargaining power between producers of intermediate and final goods. Cachon and Harker (2002) as well as Shy and Stenbacka (2003) investigate the purely strategic incentives for outsourcing within the framework of oligopoly models. Shy and Stenbacka (2005) extend the strategic analysis to a framework with a large number of potentially heterogeneous components. They characterize the equilibrium fraction of outsourced inputs within a framework where outsourcing requires monitoring costs, which increase as convex functions of the number of component-specific production lines.

The literature summarized in the previous paragraph has focused on two main issues. The first, termed the "make-or-buy" decision, has been characterized in the literature as the industry-specific circumstances under which firms choose to adopt outsourcing. The second issue concerns which types and which components to outsource. Contrary to this literature, the present analysis focuses not only on how many production lines to outsource, but also on the novel issue of how to outsource. More precisely, we characterize the efficient organization of outsourcing by comparing nested (vertical) outsourcing with horizontal outsourcing.

We construct a model in which both in-house production and outsourcing entail component-specific monitoring costs that increase as convex functions of the number of managed production lines. Furthermore, when comparing nested outsourcing with horizontal outsourcing, an important factor turns out to be to what extent managing a larger number of subcontractors imposes additional monitoring costs compared with a configuration dealing with only one supplier of components. We find nested outsourcing to be 
inefficient unless the costs of monitoring outsourcing increase sharply with the number of subcontractors and not only with the number of outsourced component-specific production lines. We characterize a market failure with nested outsourcing as the market outcome even though horizontal outsourcing is the efficient outsourcing mode. This market failure occurs for an intermediate range of the additional monitoring costs associated with outsourcing to multiple subcontractors as compared to an outsourcing structure that uses only one supplier of components.

Our study proceeds as follows. Section 2 presents the industry environment and defines the technology and costs of production and outsourcing. Sections 3 and 4 characterize efficient outsourcing as well as outsourcing generated by profit maximization for the structures with nested and horizontal outsourcing, respectively. Section 5 compares the two structures of outsourcing and identifies a market failure in which nested outsourcing is the market outcome whereas horizontal outsourcing constitutes the efficient production mode. Section 6 extends the basic model to include an endogenous determination of the fees/prices charged by outsourced firms. Section 7 offers a brief extension characterizing the optimal number of horizontal subcontractors. Finally, section 8 presents some concluding comments.

\section{Technology and Cost}

Firm 0 produces one final good. To do so, $n$ intermediate goods (components) are needed to complete the production of this final good. Let $n_{0}\left(0 \leq n_{0} \leq n\right)$ be the number of components produced by firm 0 (the root firm). Hence, this firm outsources the production of $n_{0}^{s}=n-n_{0}$ components to one or two firms, labeled as firm 1 and firm $2 .^{2}$

Our analysis distinguishes between two types of outsourcing structures, which are illustrated in Figure 1. Under nested (vertical) outsourcing (denoted by $V$ ) firm 0 , the root

\footnotetext{
${ }^{2}$ Section 7 analyzes an arbitrary number of subcontractors under horizontal outsourcing.
} 


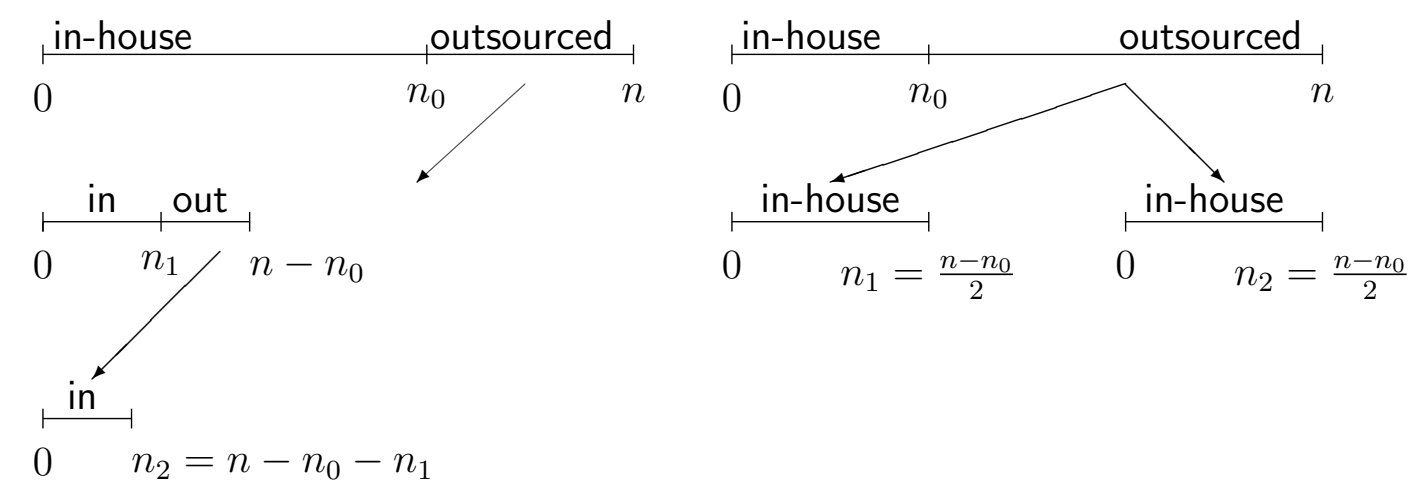

Figure 1: Left: Nested (Vertical) Outsourcing $(V)$. Right: Horizontal Outsourcing $(H)$

firm, only outsources the production of $n_{0}^{s}=n-n_{0}$ components to firm 1 . Firm 1 produces $n_{1}$ components in-house $\left(n_{1} \leq n-n_{0}\right)$ and outsources the production of $n_{1}^{s}=n-n_{0}-n_{1}$ components to firm 2. Firm 2 is the last in this chain of outsourcing and therefore does not outsource.

In contrast to nested (vertical) outsourcing, we define horizontal outsourcing ${ }^{3}$ (denoted by $H$ ) as an organizational form under which firm 0 allocates part of its production of components to more than one firm. Under this configuration, subcontractors are not allowed to further outsource any part of their component production to any other firm. Thus, under horizontal outsourcing the root firm requires exclusivity from the selected subcontractors.

Each one of the $n$ components is produced at a unit cost denoted by $\gamma, \gamma \geq 0$. All subcontractors are identical and each charges an exogenously-given price $p_{s}$ for each component. ${ }^{4}$ In addition, each firm bears a fixed cost $\phi \geq 0$ and monitoring costs. We distinguish between two types of monitoring costs: monitoring of in-house production of components and monitoring of outsourced production processes. Therefore, the total cost

\footnotetext{
${ }^{3}$ Kamien, Li, and Samet (1989) and Spiegel (1993) have introduced this concept to describe an industry configuration where two competitors in a market for a final good subcontract the provision of the final good to each other. We define this concept differently and use it to characterize the outsourcing of components (intermediate goods) in a horizontal manner as illustrated in Figure 1 (right).

${ }^{4}$ Section 6 extends the basic model to include an endogenous determination the fees/prices charged by outsourced firms.
} 
borne by firm 0 when it outsources the production of $n-n_{0}$ components is

$$
\begin{aligned}
& C_{0}\left(n_{0}\right)= \\
& \qquad \begin{cases}\phi+\gamma n_{0}+p_{s}\left(n-n_{0}\right)+\mu_{f}\left(n_{0}\right)^{2}+\mu_{s}(1)\left(n-n_{0}\right)^{2} & \text { nested outsourcing } \\
\phi+\gamma n_{0}+2 p_{s}\left(\frac{n-n_{0}}{2}\right)+\mu_{f}\left(n_{0}\right)^{2}+2 \mu_{s}(2)\left(\frac{n-n_{0}}{2}\right)^{2} & \text { horizontal outsourcing. }\end{cases}
\end{aligned}
$$

The cost function (1) reflects decreasing returns with respect to the number of components monitored. This applies to the monitoring of in-house production activities as well as outsourced production processes. The coefficient $\mu_{f} \geq 0$ determines the magnitude of in-house monitoring costs. The monitoring costs associated with outsourcing depend on the number of subcontractors with which firm 0 interacts. Under nested outsourcing, firm 0 interacts with only one subcontractor, firm 1 , in which case $\mu_{s}(1) \geq 0$ is the coefficient measuring the outsourcing monitoring costs. Under horizontal outsourcing, firm 0 contracts two suppliers, in which case $\mu_{s}(2)$ is the coefficient measuring the monitoring cost of each of the two suppliers. This specification already embeds the outcome that the two identical suppliers should be contracted to produce an equal number of components given by $n_{1}=n_{2}=\left(n-n_{0}\right) / 2$. Overall, through the combination of constant marginal costs for production and increasing marginal costs associated with monitoring the component production lines, our model is designed to focus on the effects of these monitoring costs on the efficient structure of outsourcing.

A relationship $\mu_{s}(2)>\mu_{s}(1)$ would imply that outsourcing monitoring costs increase with the number of subcontractors and not only with the number of outsourced components. The inequality $\mu_{s}(2)>\mu_{s}(1)$ would capture the idea that managing a larger number of subcontractors imposes additional monitoring costs. Related costs associated with added managerial complexity have been discussed by Fershtman and Kalai (1993) and Shy and Stenbacka (2005). Alternatively, if $\mu_{s}(2)=\mu_{s}(1)$, outsourcing monitoring costs depend only on the number of outsourced components and not on the number of suppliers. The following definition classifies the complexity associated with the monitoring of several subcontractors.

DEFINITION 1. We say that there are diseconomies (economies) with respect to the 
number of subcontractors if $\mu_{s}(2)>\mu_{s}(1)\left(\mu_{s}(2)<\mu_{s}(1)\right)$. In particular, if $\mu_{s}(2)>$ $2 \mu_{s}(1)$ we say that there are strong diseconomies with respect to the number of subcontractors.

In view of figure 1 , under nested outsourcing firm 1 produces $n_{1}$ components in-house, and outsources $n-n_{0}-n_{1}$ production processes to firm 2. Under horizontal outsourcing firm 1 and firm 2 each produces $n_{1}=\left(n-n_{0}\right) / 2$ components with no further outsourcing. Therefore, the total cost borne by firm 1 is

$$
\begin{aligned}
& C_{1}\left(n_{1}, n_{0}\right)= \\
& \begin{cases}\phi+\gamma n_{1}+p_{s}\left(n-n_{0}-n_{1}\right)+\mu_{f}\left(n_{1}\right)^{2}+\mu_{s}(1)\left(n-n_{0}-n_{1}\right)^{2} & \text { nested outsourcing } \\
\phi+\gamma\left(\frac{n-n_{0}}{2}\right)+\mu_{f}\left(\frac{n-n_{0}}{2}\right)^{2} & \text { horizontal outsourcing. }\end{cases}
\end{aligned}
$$

Finally, firm 2 does not outsource production of components regardless of the type of the outsourcing pattern and therefore does not bear any outsourcing monitoring cost. Thus,

$$
C_{2}\left(n_{1}, n_{0}\right)= \begin{cases}\phi+\gamma\left(n-n_{0}-n_{1}\right)+\mu_{f}\left(n-n_{0}-n_{1}\right)^{2} & \text { nested outsourcing } \\ \phi+\gamma\left(\frac{n-n_{0}}{2}\right)+\mu_{f}\left(\frac{n-n_{0}}{2}\right)^{2} & \text { horizontal outsourcing. }\end{cases}
$$

Notice that the subcontractors firm 1 and firm 2 bear the same costs under horizontal outsourcing because they produce the same number of components. Therefore the bottom lines of (2) and (3) are equal.

\section{Nested Outsourcing}

This section analyzes efficient outsourcing levels as well the outsourcing level that maximizes the profit for firm 0 under nested outsourcing.

\subsection{Efficient nested outsourcing}

In this paper the efficient distribution of component production among the firms is determined by maximizing the sum of profits of the final good producer $\left(\pi_{0}\right)$ and the subcon- 
tractors $\left(\pi_{1}, \pi_{2}\right)$, denoted by $\Pi=\pi_{0}+\pi_{1}+\pi_{2}$. Let $p$ denote the exogenously-given price that firm 0 sells its final good. Then, efficient nested outsourcing is obtained by solving

$$
\begin{aligned}
\max _{n_{0}, n_{1}} \Pi^{V}\left(n_{0}, n_{1}\right) & =p-\left[\phi+\gamma n_{0}+p_{s}\left(n-n_{0}\right)+\mu_{f}\left(n_{0}\right)^{2}+\mu_{s}(1)\left(n-n_{0}\right)^{2}\right] \\
+p_{s}\left(n-n_{0}\right) & -\left[\phi+\gamma n_{1}+p_{s}\left(n-n_{0}-n_{1}\right)+\mu_{f}\left(n_{1}\right)^{2}+\mu_{s}(1)\left(n-n_{0}-n_{1}\right)^{2}\right] \\
+ & p_{s}\left(n-n_{0}-n_{1}\right)-\left[\phi+\gamma\left(n-n_{0}-n_{1}\right)+\mu_{f}\left(n-n_{0}-n_{1}\right)^{2}\right] .
\end{aligned}
$$

Observe that all expenditures on outsourcing equal subcontractors' revenues. Therefore, in (4) all terms with $p_{s}$ cancel out. The unique solution to (4) is

$$
\begin{aligned}
& n_{0}^{V}=\frac{n\left\{\left(\mu_{f}\right)^{2}+3 \mu_{f} \mu_{s}(1)+\left[\mu_{s}(1)\right]^{2}\right\}}{\left[\mu_{f}+\mu_{s}(1)\right]\left[3 \mu_{f}+\mu_{s}(1)\right]}, \quad n_{1}^{V}=\frac{n \mu_{f}}{3 \mu_{f}+\mu_{s}(1)} \\
& \text { and hence } \quad n_{2}^{V}=\frac{n\left(\mu_{f}\right)^{2}}{\left[\mu_{f}+\mu_{s}(1)\right]\left[3 \mu_{f}+\mu_{s}(1)\right]} .
\end{aligned}
$$

Substituting the numbers of in-house production lines (5) into (4) yields the sum of firms' profits under nested outsourcing. Thus,

$$
\Pi^{V}=p-3 \phi-\gamma n-\frac{n^{2} \mu_{f}\left\{\left(\mu_{f}\right)^{2}+3 \mu_{f} \mu_{s}(1)+\left[\mu_{s}(1)\right]^{2}\right\}}{\left[\mu_{f}+\mu_{s}(1)\right]\left[3 \mu_{f}+\mu_{s}(1)\right]} .
$$

Comparing the number of components produced by each firm under nested vertical outsourcing given in (5) yields

$$
\begin{aligned}
& n_{0}^{V}-n_{1}^{V}=\frac{n \mu_{s}(1)\left[2 \mu_{f}+\mu_{s}(1)\right]}{\left[\mu_{f}+\mu_{s}(1)\right]\left[3 \mu_{f}+\mu_{s}(1)\right]} \geq 0 \quad \text { and } \\
& \qquad n_{1}^{V}-n_{2}^{V}=\frac{n \mu_{f} \mu_{s}(1)}{\left[\mu_{f}+\mu_{s}(1)\right]\left[3 \mu_{f}+\mu_{s}(1)\right]} \geq 0 .
\end{aligned}
$$

The above inequalities are strict if $\mu_{s}(1)>0$. The following result characterizes the efficient in-house production levels under the nested (vertical) outsourcing structure.

Result 1. Under nested outsourcing, firms that are higher on the outsourcing ladder produce a larger number of components than firms that are lower on the outsourcing ladder. The differences between in-house production levels among firms become larger with an increase in the magnitude of the cost of monitoring outsourced activities, as 
captured by the parameter $\mu_{s}(1)$. In contrast, in the absence of outsourcing monitoring costs $\left(\mu_{s}(1)=0\right.$ ) all firms produce an equal number of components ( $n_{0}^{V}=n_{1}^{V}=n_{2}^{V}=$ $n / 3)$.

The intuition behind result 1 is as follows. In the absence of outsourcing monitoring costs $\left(\mu_{s}(1)=0\right)$, the sum of profits is maximized by equally distributing the number of components produced by each firm on the outsourcing ladder. However, in the presence of outsourcing monitoring costs $\left(\mu_{s}(1)>0\right)$, joint profit is maximized when the root firm produces more components in-house than what is outsourced to firm 1 . Under nested outsourcing the root firm manages more production lines than the second firm in the chain of outsourcing, and firm 1 produces more than firm 2. Note that under nested vertical outsourcing firm 0 bears the highest monitoring costs since it must monitor all of its outsourced production activities including those activities that are subsequently outsourced by firm 1 to firm 2 . In this respect, with nested outsourcing there is a duplication of outsourcing monitoring effort exerted by firm 0 and firm 1 . Firm 1 bears lower outsourcing monitoring costs, and firm 2 bears only in-house production monitoring costs since it does not outsource any production activities.

\subsection{Profit-maximizing nested outsourcing}

Suppose now that firm 0 and firm 1 make their own separate outsourcing decisions in order to maximize their own profits. More precisely, firm 0 sets $n_{0}$ to maximize $\pi_{0}$, and then firm 1 sets $n_{1}$ to maximize $\pi_{1}$ taking $n_{0}$ as given.

From the first row of (4), firm 0 chooses its in-house production level $n_{0}$ to solve

$$
\max _{n_{0}} \pi_{0}=p-\left[\phi+\gamma n_{0}+p_{s}\left(n-n_{0}\right)+\mu_{f}\left(n_{0}\right)^{2}+\mu_{s}(1)\left(n-n_{0}\right)^{2}\right]
$$

yielding

$$
n_{0}=\frac{2 n \mu_{s}(1)+p_{s}-\gamma}{2\left[\mu_{f}+\mu_{s}(1)\right]} .
$$


The resulting profit level of firm 0 is

$$
\pi_{0}^{V}=p-\phi-\frac{4 n^{2} \mu_{f} \mu_{s}(1)+4 n\left[p_{s} \mu_{f}+\gamma \mu_{s}(1)\right]-\left(p_{s}-\gamma\right)^{2}}{4\left[\mu_{f}+\mu_{s}(1)\right]} .
$$

This is the equilibrium profit for firm 0 under nested outsourcing. Section 5 below compares this equilibrium profit with the profit generated under horizontal outsourcing.

\section{Horizontal Outsourcing}

Horizontal outsourcing is illustrated in the right part of figure 1 . The root firm, firm 0 , produces $n_{0}\left(0 \leq n_{0} \leq n\right)$ components in-house and divides the remaining $n-n_{0}$ production activities among all subcontractors (firm 1 and firm 2 in the present case). These subcontractors are not permitted to further outsource production of components. Hence, only firm 0 bears the cost of monitoring outsourcing activities. The sum of these outsourcing costs equals $2 \mu_{s}(2)\left[\left(n-n_{0}\right) / 2\right]^{2}$, which incorporates the idea that the outsourced components are equally split between firm 1 and firm 2. The factor $\mu_{s}(2)$ captures the costs associated with monitoring two different subcontractors.

\subsection{Efficient horizontal outsourcing}

Efficient horizontal outsourcing is determined by maximizing the sum of all profits. Formally, the efficient allocation of component production is obtained by solving

$$
\begin{aligned}
\max _{n_{0}} \Pi^{H}\left(n_{0}\right)=p & -\left[\phi+\gamma n_{0}+p_{s}\left(n-n_{0}\right)+\mu_{f}\left(n_{0}\right)^{2}+2 \mu_{s}(2)\left(\frac{n-n_{0}}{2}\right)^{2}\right] \\
+ & 2\left\{p_{s}\left(\frac{n-n_{0}}{2}\right)-\left[\phi+\gamma\left(\frac{n-n_{0}}{2}\right)+\mu_{f}\left(\frac{n-n_{0}}{2}\right)^{2}\right]\right\} .
\end{aligned}
$$

The top row is the profit of firm 0 taking into consideration that the firm bears two separate outsourcing monitoring costs. Under horizontal outsourcing, firm 0 contracts with two independent subcontractors in contrast to nested outsourcing where firm 0 contracts with one supplier only. The second line in (11) is the profit made by a subcontractor multiplied 
by two to reflect that there are two symmetric subcontractors. Again, observe that the outsourcing bills are equal to subcontractors' revenues. Therefore, in (11) all terms with $p_{s}$ cancel out. The unique solution to $(11)$ is

$$
n_{0}^{H}=\frac{n\left[\mu_{f}+\mu_{s}(2)\right]}{3 \mu_{f}+\mu_{s}(2)} \quad \text { and } \quad n_{1}^{H}=n_{2}^{H}=\frac{n \mu_{f}}{3 \mu_{f}+\mu_{s}(2)} .
$$

Substituting the efficient number of in-house production lines (12) into the sum of profits (11) yields

$$
\Pi^{H}=p-3 \phi-\gamma n-\frac{n^{2} \mu_{f}\left[\mu_{f}+\mu_{s}(2)\right]}{3 \mu_{f}+\mu_{s}(2)} .
$$

Comparing the number of goods produced by each firm under horizontal outsourcing implies the following result.

Result 2. Under horizontal outsourcing, efficient allocation of component production requires that firm 0 outsources more than 50 percent of the components if and only if $\mu_{f}>\mu_{s}(2)$.

From (12) we can also conclude that efficient organization of component production under horizontal outsourcing means that each firm produces an equal number of components if there are no outsourcing monitoring costs $\left(\mu_{s}(2)=0\right)$. As $\mu_{s}(2)$ increases, outsourcing activities diminish and efficiency is maintained at a lower level of outsourcing with more components produced in-house by firm 0 .

\subsection{Profit-maximizing horizontal outsourcing}

Suppose now that firm 0 makes its outsourcing decision so as to maximize its own profit only. More precisely, firm 0 sets $n_{0}$ to maximize $\pi_{0}$. From the first row of (11), firm 0 chooses its in-house production level $n_{0}$ to solve

$$
\max _{n_{0}} \pi_{0}=p-\left[\phi+\gamma n_{0}+p_{s}\left(n-n_{0}\right)+\mu_{f}\left(n_{0}\right)^{2}+2 \mu_{s}(2)\left(\frac{n-n_{0}}{2}\right)^{2}\right],
$$

yielding

$$
n_{0}=\frac{n \mu_{s}(2)+p_{s}-\gamma}{2 \mu_{f}+\mu_{s}(2)}
$$


The resulting profit level of firm 0 is

$$
\pi_{0}^{H}=p-\phi-\frac{2 n^{2} \mu_{f} \mu_{s}(2)+2 n\left[2 p_{s} \mu_{f}+\gamma \mu_{s}(2)\right]-\left(p_{s}-\gamma\right)^{2}}{2\left[2 \mu_{f}+\mu_{s}(2)\right]} .
$$

Equation (16) is the equilibrium profit of firm 0 under horizontal outsourcing. Section 5 compares this profit with the profit generated under nested outsourcing.

\section{Comparisons of Outsourcing Patterns}

\subsection{A comparison of efficient allocations}

We now compare the efficient number of outsourced components under nested outsourcing with that of horizontal outsourcing. Comparing (5) with (12) yields

$$
n_{0}^{V}-n_{0}^{H}=\frac{n \mu_{f}\left\{\mu_{f}\left[5 \mu_{s}(1)-2 \mu_{s}(2)\right]+\mu_{s}(1)\left[2 \mu_{s}(1)-\mu_{s}(2)\right]\right\}}{\left[\mu_{f}+\mu_{s}(1)\right]\left[3 \mu_{f}+\mu_{s}(1)\right]\left[3 \mu_{f}+\mu_{s}(2)\right]}>0
$$

if and only if

$$
\mu_{s}(2)<\bar{\mu}_{s}(2) \stackrel{\text { def }}{=} \frac{\mu_{s}(1)\left[5 \mu_{f}+2 \mu_{s}(1)\right]}{2 \mu_{f}+\mu_{s}(1)} .
$$

We can therefore state the third result.

Result 3. It is efficient to outsource a smaller fraction of production lines under nested outsourcing compared with horizontal outsourcing if and only if $\mu_{s}(2)<\bar{\mu}_{s}(2)$.

Comparing (6) to (13), we obtain

$$
\Pi^{V}-\Pi^{H}=\frac{n^{2}\left(\mu_{f}\right)^{2}\left\{\mu_{f}\left[2 \mu_{s}(2)-5 \mu_{s}(1)\right]+\mu_{s}(1)\left[\mu_{s}(2)-2 \mu_{s}(1)\right]\right\}}{\left[\mu_{f}+\mu_{s}(1)\right]\left[3 \mu_{f}+\mu_{s}(1)\right]\left[3 \mu_{f}+\mu_{s}(2)\right]} .
$$

Therefore,

Result 4. Nested outsourcing is inefficient relative to horizontal outsourcing if and only if $\mu_{s}(2)<\bar{\mu}_{s}(2)$.

Under condition (18) efficiency requires less outsourcing under the nested structure compared with the horizontal structure because nested outsourcing generates duplication of 
outsourcing monitoring costs. That is, in view of figure 1 (left), firm 0 bears monitoring costs of all outsourced production lines in this industry. Duplication arises as firm 0 and firm 1 both monitor the production lines outsourced to firm 2. However if the cost of monitoring two subcontractors is very high so that condition (18) is reversed, nested outsourcing becomes efficient. Thus, nested outsourcing can be efficient only if there are significant diseconomies with respect to the number of subcontractors (see Definition 1). This is because the increased complexity associated with monitoring two component suppliers makes horizontal outsourcing inefficient when $\mu_{s}(2)>\bar{\mu}_{s}(2)$. As pointed out by a referee, this conclusion seems very intuitive as our model has an exclusive focus on how the monitoring costs associated with component production lines depend on the structure of outsourcing.

Result 4 implies the following corollary, given as result 5.

Result 5. Nested outsourcing is inefficient relative to horizontal outsourcing when outsourcing monitoring costs depend only on the number of outsourced components and not on the number of suppliers, formally when $\mu_{s}(2)=\mu_{s}(1)$.

Table 1 compares the number of components produced in-house and the sum of profits under nested and horizontal outsourcing for some extreme combinations of monitoring cost parameters. Table 1 assumes that $\mu_{s} \stackrel{\text { def }}{=} \mu_{s}(2)=\mu_{s}(1)$, which means, by definition 1 , that there are no economies or diseconomies with respect to the number of subcontractors.

Table 1 demonstrates that in the absence of outsourcing monitoring costs $\left(\mu_{s}=0\right)$, or in the absence of in-house monitoring costs $\left(\mu_{f}=0\right)$, efficiency mandates the same allocation of component production under nested and horizontal outsourcing. Under these cases, the sums of profits are also identical. When $\mu_{s}=0$, efficiency implies that an equal number of components should be produced by all firms. This happens because in the absence of outsourcing monitoring costs, in-house monitoring costs are minimized when production activities are equally divided among all firms under both nested and horizontal outsourcing structures. 


\begin{tabular}{c|cccc} 
Parameters & $n_{0}$ & $n_{1}$ & $n_{2}$ & $\pi_{0}+\pi_{1}+\pi_{2}$ \\
\hline \multicolumn{5}{c}{ Nested Vertical Outsourcing } \\
$\mu_{f}=\mu_{s}=\mu$ & $5 n / 8$ & $n / 4$ & $n / 8$ & $p-3 \phi-\gamma n-5 n^{2} \mu / 8$ \\
$\mu_{s}=0$ & $n / 3$ & $n / 3$ & $n / 3$ & $p-3 \phi-\gamma n-n^{2} \mu_{f} / 3$ \\
$\mu_{f}=0$ & $n$ & 0 & 0 & $p-3 \phi-\gamma n$ \\
\multicolumn{1}{c}{ Horizontal Outsourcing } \\
$\mu_{f}=\mu_{s}=\mu$ & $n / 2$ & $n / 4$ & $n / 4$ & $p-3 \phi-\gamma n-n^{2} \mu / 2$ \\
$\mu_{s}=0$ & $n / 3$ & $n / 3$ & $n / 3$ & $p-3 \phi-\gamma n-n^{2} \mu_{f} / 3$ \\
$\mu_{f}=0$ & $n$ & 0 & 0 & $p-3 \phi-\gamma n$ \\
\hline
\end{tabular}

Table 1: A Comparison of Efficient Nested and Horizontal Outsourcing Under $\mu_{s}(2)=\mu_{s}(1)$

In the other extreme case in which there are no in-house monitoring costs $\left(\mu_{f}=0\right)$, outsourcing monitoring costs can be completely eliminated by having firm 0 producing all components. Finally, the case of symmetric monitoring costs in which $\mu_{f}=\mu_{s}=\mu$ confirms Result 3 stating that the efficient level of outsourcing is lower under nested outsourcing than under horizontal outsourcing. Similarly, with efficient outsourcing, the sum of profits is lower under nested outsourcing than under horizontal outsourcing when $\mu_{s}(2)=\mu_{s}(1)$, which is consistent with results 4 and 5 .

\subsection{The profit-maximizing mode of outsourcing for firm 0}

Suppose now that firm 0 has to choose whether to adopt a nested or a horizontal outsourcing structure in order to maximize its own profit. To analyze the profit-maximizing mode of outsourcing for firm 0 , we compare the profit of firm 0 under nested and horizontal outsourcing when it determines its own in-house production level $n_{0}$.

Comparing (10) with (16), we find

$$
\pi_{0}^{V}-\pi_{0}^{H}=\frac{\left[\mu_{s}(2)-2 \mu_{s}(1)\right]\left(2 n \mu_{f}-p_{s}+\gamma\right)^{2}}{4\left[\mu_{f}+\mu_{s}(1)\right]\left[2 \mu_{f}+\mu_{s}(2)\right]} .
$$

The difference in profits (20) is positive if $\mu_{s}(2)>2 \mu_{s}(1)$, that is, if there are strong 
diseconomies with respect to the number of subcontractors. This means that the profitmaximizing mode of outsourcing is determined simply by whether or not there are strong diseconomies of with respect to the number of subcontractors. Notice that this result does not depend on the aggregate number of components $n$ despite the fact that the equilibrium profit levels (10) and (16) do vary with $n$. We can therefore state the following result.

Result 6. Nested outsourcing is more profitable to firm 0 than horizontal outsourcing if there are strong diseconomies with respect to the number of subcontractors.

Result 6 also implies that horizontal outsourcing is the profitable mode for firm 0 if there are no strong diseconomies, as classified in definition 1.

\subsection{Profit maximization and efficiency}

We now investigate whether the profit-maximizing choice of outsourcing mode made by firm 0 is efficient. More precisely, does the outsourcing mode which maximizes the profit of firm 0 also maximizes the sum of profits of all firms?

To investigate this problem we compare (19) with (20). Figure 2 illustrates firm 0's profit-maximizing choice as well as the efficient choice for varying values of $\mu_{s}(2)$ and $\mu_{s}(1)$.

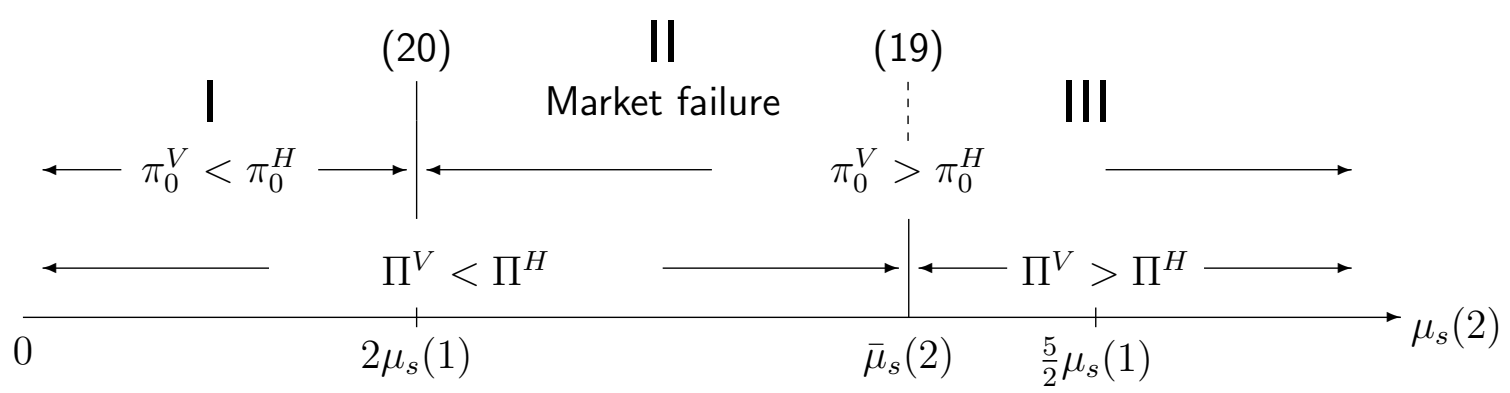

Figure 2: Profit maximization and efficiency

In region I $\left(\mu_{s}(2)<2 \mu_{s}(1)\right)$ firm 0 earns a higher profit under horizontal outsourcing compared with nested outsourcing. In this region horizontal outsourcing is also the 
efficient mode of outsourcing. In region III $\left(\mu_{s}(2)>\bar{\mu}_{s}(2), \bar{\mu}_{s}(2)\right.$ is defined in (18)) nested outsourcing is efficient and in addition firm 0 earns a higher profit under nested outsourcing. Consequently, in regions I and III the market outcome as dictated by firm 0 is efficient. In contrast, in region II horizontal outsourcing is efficient whereas firm 0 prefers nested outsourcing over horizontal outsourcing. Thus, in region II a market failure is realized, as expressed in result 7 .

Result 7. For $2 \mu_{s}(1)<\mu_{s}(2)<\bar{\mu}_{s}(2)$ there is a market failure because nested outsourcing is the market outcome but horizontal outsourcing is the efficient outcome.

Why is there a market failure in region II? As $\mu_{s}(2)$ gradually increases relative to $\mu_{s}(1)$ and enters the region of diseconomies with respect to the number of subcontractors, firm 0 switches to nested outsourcing. Nested outsourcing generates duplication of monitoring costs for those components that are monitored by firm 0 and firm 1 . The duplication of outsourcing monitoring costs is not internalized by firm 0 , and this is the source of inefficiency that leads to this market failure. However, with a further increase in $\mu_{s}(2)$, horizontal outsourcing becomes increasingly costly, and as region III is reached the cost of monitoring two suppliers $\mu_{s}(2)$ dominates the monitoring duplication costs, which makes nested outsourcing the efficient outcome.

\section{Endogenous Prices of Outsourced Components}

So far, our analysis is based on the assumption that each subcontractor charges an exogenously-given price, $p_{s}$, for each component supplied to the final good producer. The advantage with an analysis focusing on exogenously-given price is that it avoids specifying the precise mechanism for how component prices are determined. Thus, our analysis so far has not relied on any specific market structure and any specification of the relative bargaining powers between the final good producer and the subcontractor(s). Clearly, in a more general setup, component prices would typically differ between horizontal and nested (vertical) outsourcing under almost any market structure. 
One extreme market structure would be to allocate all the bargaining power to the outsourcing firm, firm 0 , (or firms, in the case of nested outsourcing). Under such an assumption, firms which are "more upstream" would make take-it-or-leave-it offers to subcontractor(s) located "more downstream." The opposite extreme would be to give all bargaining power to subcontractors, which would then make take-it-or-leave-it offers to the "more upstream" firms. This type of market structure is often used to model the "holdup problem," where suppliers extract all surplus from the outsourcing firm by threatening to cut the supply of parts.

This section adopts an intermediate approach to determining the choice of market structure and solves for the competitive market-clearing price of outsourced components under nested (vertical) and horizontal outsourcing. Thus, the framework we develop here frees us from having to allocate bargaining power between the parties in an arbitrary way. We focus on an industry with a large number of symmetric and standardized components. We assume that all subcontractors have the capability of producing any component, meaning that there is no irreversible matching between a particular pair of subcontractor and an individual component's production line. Here, following sections 3.2 and 4.2 , all firms (final goods producers and subcontractors) are price takers and select the amount they wish to outsource under a given competitive per-component price. We then ask which price $\left(p_{s}\right)$ would clear the market for outsourced components so that the total demand for outsourced components by final goods producers would equal the aggregate supply of profit-maximizing subcontractors.

\subsection{Outsourcing pricing: Nested (vertical) outsourcing}

Firm 0's profit-maximizing choice of how many components to outsource was already analyzed in section 3.2. We therefore proceed to the profit-maximization outsourcing problem solved by firm 1 . In view of figure 1 (left), firm 1 supplies $n-n_{0}$ components to firm 0 and chooses the number of components to produce in house $\left(n_{1}\right)$ and how many components to outsource to firm $2\left(n-n_{0}-n_{1}\right)$, where $n_{0}$ is given by (9). Formally, 
firm 1 takes $n-n_{0}$ and $p_{s}$ as given and chooses $n_{1}$ to solve

$$
\begin{aligned}
\max _{n_{1}} \pi_{1}=p_{s} & \left(n-n_{0}\right) \\
- & {\left[\phi+\gamma n_{1}+\mu_{f}\left(n_{1}\right)^{2}+\mu_{s}(1)\left(n-n_{0}-n_{1}\right)^{2}+p_{s}\left(n-n_{0}-n_{1}\right)\right] . }
\end{aligned}
$$

The first term describes the revenue earned from supplying $n-n_{0}$ components to firm 0 . The second term is firm 1's total cost given in (2). Substituting $n_{0}$ from (9) and solving (21), the number of components produced in house by firm 1 is

$$
n_{1}^{V}=\frac{\mu_{f}\left[2 n \mu_{s}(1)+p_{s}-\gamma\right]}{2\left[\mu_{f}+\mu_{s}(1)\right]^{2}} .
$$

Figure 1 (left) shows that firm 2, the "most downstream" firm, does not outsource to other firms. Thus, firm 2 takes the component price $p_{s}$ as given and chooses how many components to produce for firm 1 . Formally, firm 2 chooses $n_{2}$ to solve

$$
\max _{n_{2}} \pi_{2}=p_{s} n_{2}-\left[\phi+\gamma n_{2}+\mu_{f}\left(n_{2}\right)^{2}\right]
$$

The first term is the revenue from supplying $n_{2}$ components to firm 1 . The second term is the cost of producing $n_{2}$ components similar to cost structure in (3). The solution to (23) is given by

$$
n_{2}^{V}=\frac{p_{s}-\gamma}{2 \mu_{f}}
$$

To find the component price, $p_{s}$, which clears the market for outsourced components, substituting (9), (22), and (24) into the market clearing condition, $n_{0}^{V}+n_{1}^{V}+n_{2}^{V}=n$ yields

$$
p_{S}^{V}=\gamma+\frac{2 n\left(\mu_{f}\right)^{3}}{3\left(\mu_{f}\right)^{2}+3 \mu_{f} \mu_{s}(1)+\left[\mu_{s}(1)\right]^{2}} .
$$

Since $p_{S}^{V}>\gamma$ we can conclude that the market-clearing price for outsourced components exceeds the marginal production cost of a component, $\gamma$. This result captures the idea that the equilibrium price must also cover the monitoring costs. Substituting the marketclearing price (25) into equations (9), (22), and (24) lets us obtain the equilibrium number 
of components produced by each firm under the market-clearing price. Thus,

$$
\begin{aligned}
n_{0}^{V}=\frac{n\left[\left(\mu_{f}\right)^{2}+2 \mu_{f} \mu_{s}(1)+\left[\mu_{s}(1)\right]^{2}\right]}{3\left(\mu_{f}\right)^{2}+3 \mu_{f} \mu_{s}+\left[\mu_{s}(1)\right]^{2}}, & n_{1}^{V}=\frac{n \mu_{f}\left[\mu_{f}+\mu_{s}(1)\right]}{3\left(\mu_{f}\right)^{2}+3 \mu_{f} \mu_{s}(1)+\left[\mu_{s}(1)\right]^{2}} \\
& \text { and } \quad n_{2}^{V}=\frac{n\left(\mu_{f}\right)^{2}}{3\left(\mu_{f}\right)^{2}+3 \mu_{f} \mu_{s}+\left[\mu_{s}(1)\right]^{2}}
\end{aligned}
$$

\subsection{Outsourcing pricing: Horizontal outsourcing}

In view of Figure 1 (right), firm 1 supplies $n_{1}$ and firm 2 supplies $n_{2}$ components directly to firm 0 . Given by (15), firm 0 produces $n_{0}$ components in-house. Thus, each subcontractor $i=1,2$, takes $p_{s}$ as given and chooses $n_{i}$ to solve

$$
\max _{n_{i}} \pi_{i}=p_{s} n_{i}-\left[\phi+\gamma n_{i}+\mu_{f}\left(n_{i}\right)^{2}\right]
$$

yielding

$$
n_{1}^{H}=n_{2}^{H}=\frac{p_{s}-\gamma}{2 \mu_{f}}
$$

To find the component price, $p_{s}$, which clears the market for outsourced components, substitute (15) and (28) into the market clearing condition, $n_{0}+n_{1}+n_{2}=n$ to obtain

$$
p_{S}^{H}=\gamma+\frac{2 n\left(\mu_{f}\right)^{2}}{3 \mu_{f}+\mu_{s}(2)} .
$$

Notice again that $p_{S}^{H}>\gamma$, which implies that the market-clearing price for outsourced components must also cover the monitoring costs in addition to the marginal production cost, $\gamma$. Substituting the market-clearing price (29) into (15) and (28) obtains the equilibrium number of components produced by each firm at the market clearing price under horizontal outsourcing. Thus,

$$
n_{0}^{H}=\frac{n\left[\mu_{f}+\mu_{s}(2)\right]}{3 \mu_{f}+\mu_{s}(2)} \quad \text { and } \quad n_{1}^{H}=n_{2}^{H}=\frac{n \mu_{f}}{3 \mu_{f}+\mu_{s}(2)} .
$$

\subsection{Comparing component prices: Nested versus horizontal}

At this point it is natural to ask the following questions: How does the outsourcing structure affect the price of outsourced components? What is the relationship between 
in-house production under nested and horizontal outsourcing under competitive prices for the outsourced components? To answer these questions we initially subtract (25) from (29). This procedure yields the following price difference

$$
p_{s}^{H}-p_{s}^{V}=\frac{2 n\left(\mu_{f}\right)^{2}\left\{\left[\mu_{s}(1)\right]^{2}+\mu_{f}\left[3 \mu_{s}(1)-\mu_{s}(2)\right]\right\}}{\left[3 \mu_{f}+\mu_{s}(2)\right]\left\{3\left(\mu_{f}\right)^{2}+3 \mu_{f} \mu_{s}(1)+\left[\mu_{s}(1)\right]^{2}\right\}} .
$$

From equation (31) we can conclude that the competitive component price under horizontal outsourcing exceeds that associated with nested outsourcing unless there are sufficiently strong diseconomies with respect to the number of subcontractors. More precisely, the competitive component price under horizontal outsourcing exceeds (falls short of) that associated with nested outsourcing if and only if

$$
\mu_{s}(2)<(>) 3 \mu_{s}(1)+\frac{\left[\mu_{s}(1)\right]^{2}}{\mu_{f}} .
$$

Similarly, subtracting (30) from (26) we find out that

$$
n_{0}^{V}-n_{0}^{H}=\frac{n \mu_{f}\left\{\mu_{s}(1)\left[2 \mu_{s}(1)-\mu_{s}(2)\right]+\mu_{f}\left[3 \mu_{s}(1)-2 \mu_{s}(2)\right]\right\}}{\left[3 \mu_{f}+\mu_{s}(2)\right]\left\{3\left(\mu_{f}\right)^{2}+3 \mu_{f} \mu_{s}(1)+\left[\mu_{s}(1)\right]^{2}\right\}} .
$$

From (33) we can conclude that the degree of outsourcing is determined by the magnitude of diseconomies of scale with respect to the number of subcontractors. More precisely, with competitive component prices the final good producer outsources a higher proportion of the components under horizontal outsourcing than under nested outsourcing $\left(n_{0}-n_{0}^{H}>\right.$ $\left.n_{0}-n_{0}^{V}\right)$ if

$$
\mu_{s}(2)<m\left(\mu_{s}(1), \mu_{f}\right) \mu_{s}(1) \quad \text { where } m\left(\mu_{s}(1), \mu_{f}\right) \stackrel{\text { def }}{=} \frac{2 \mu_{s}(1)+3 \mu_{f}}{\mu_{s}(1)+2 \mu_{f}} .
$$

It can be verified that the parameter $m\left(\mu_{s}(1), \mu_{f}\right)$, defined in (34), satisfies $3 / 2<$ $m\left(\mu_{s}(1), \mu_{f}\right)<2$.

We summarize our results as follows.

Result 8. (a) The competitive component price under horizontal outsourcing exceeds the price under nested outsourcing unless there are sufficiently strong diseconomies with respect to the number of subcontractors. 
(b) With competitive component prices the final good producer outsources a higher proportion of the components under horizontal outsourcing than under nested outsourcing $\left(n_{0}-n_{0}^{H}>n_{0}-n_{0}^{V}\right)$ unless the diseconomies of scale with respect to the number of subcontractors exceeds the moderate threshold characterized in (34).

From result 8 we can conclude that the differences in prices and the number of outsourced components between the horizontal and nested outsourcing structures are affected mainly by the degree of diseconomies with respect to the number of subcontractors. It should be emphasized that the threshold above which nested outsourcing generates a higher competitive component price is much higher than the threshold above which nested structure generates a higher proportion of outsourced components.

It is interesting to explore the welfare implications of (34) in light of the socially efficient outsourcing pattern characterized in section 5, as illustrated in figure 2. According to equation (34), with competitive component prices the final good producer outsources a higher fraction of the components under horizontal outsourcing than under nested outsourcing if $\mu_{s}(2)<m\left(\mu_{s}(1), \mu_{f}\right) \mu_{s}(1)$. Under these circumstances horizontal outsourcing is also more efficient than nested outsourcing. However, for configurations with $m\left(\mu_{s}(1), \mu_{f}\right) \mu_{s}(1)<\mu_{s}(2)<2 \mu_{s}(1)$ the final good producer outsources a higher proportion under nested outsourcing than with horizontal outsourcing even though horizontal outsourcing would be socially efficient.

\section{Efficient Number of Subcontractors Under Horizon- tal Outsourcing: An Extension}

This section deviates from this paper's main purpose of investigating the possibility of a market failure associated with the chosen outsourcing production mode. Yet, it turned out that the framework developed in this paper incorporates a method for computing the efficient number of subcontractors under horizontal outsourcing. We discuss this corollary result in this section. 
In view of figure 1 , we now ask how many components $n_{0}\left(n_{0} \leq n\right)$ should firm 0 produce in house, and how many subcontractors the firm should outsource the production of the remaining $n-n_{0}$ components.

Let $M$ denote the number of symmetric subcontractors. In what follows we disregard economies and diseconomies with respect to the number of subcontractors as described in Definition 1 and simply assume that $\mu_{s}=\mu_{s}(1)=\mu_{s}(2)=\cdots=\mu_{s}(M)$. In view of the sum of profits under $M=2$ given by (11), the maximization of the sum of profits in the general case is given by

$$
\begin{aligned}
& \max _{M, n_{0}} \Pi=\sum_{i=0}^{M} \pi_{i} \\
& \quad=p-\left[(M+1) \phi+\gamma n+\mu_{f}\left(n_{0}\right)^{2}+M \mu_{s}\left(\frac{n-n_{0}}{M}\right)^{2}+M \mu_{f}\left(\frac{n-n_{0}}{M}\right)^{2}\right] .
\end{aligned}
$$

The aggregate industry cost function (35) is globally concave in $M$ and $n_{0}$ because

$$
\begin{array}{r}
\frac{\partial^{2} \Pi}{\partial M^{2}}=-\frac{2\left(n-n_{0}\right)^{2}\left(\mu_{f}+\mu_{s}\right)}{M^{3}}<0, \quad \frac{\partial^{2} \Pi}{\partial n_{0}^{2}}=-\frac{2\left(M \mu_{f}+\mu_{f}+\mu_{s}\right]}{M}<0, \quad \text { and } \\
\left(\frac{\partial^{2} \Pi}{\partial M^{2}}\right)\left(\frac{\partial^{2} \Pi}{\partial n_{0}^{2}}\right)-\left(\frac{\partial^{2} \Pi}{\partial M \partial n_{0}}\right)=\frac{4 \mu_{f}\left(n-n_{0}\right)^{2}\left(\mu_{f}+\mu_{s}\right)}{M^{3}}>0 .
\end{array}
$$

Therefore, the two first-order conditions associated with (35) yield the efficient number of subcontractors as well as the number of components produced in-house,

$$
M=n \sqrt{\frac{\mu_{f}+\mu_{s}}{\phi}}-\frac{\mu_{s}}{\mu_{f}}-1 \quad \text { and } \quad n_{0}=\frac{\sqrt{\phi\left(\mu_{f}+\mu_{s}\right)}}{\mu_{f}} .
$$

For convenience, $M$ (number of subcontracted firms) is approximated by a real number. If $M<0$ in (37), there is no outsourcing so that $M=0$ and $n_{0}=n$.

Equation (37) explicitly characterizes the efficient number of symmetric subcontractors under horizontal outsourcing as well as the efficient number of outsourced components. Differentiating (37) yields

$$
\frac{\partial n_{0}}{\partial \mu_{f}}=-\frac{\mu_{f}+2 \mu_{s}}{2\left(\mu_{f}\right)^{2} \sqrt{\frac{\mu_{f}+\mu_{s}}{\phi}}}<0 \quad \text { and } \quad \frac{\partial n_{0}}{\partial \mu_{s}}=\frac{1}{2 \mu_{f} \sqrt{\frac{\mu_{f}+\mu_{s}}{\phi}}}>0
$$


Therefore under horizontal outsourcing with an efficient number of subcontractors, the efficient in-house production of components produced by the root firm $n_{0}$ declines with an increase in the in-house monitoring costs $\mu_{f}$, and increases with the outsourcing monitoring cost $\mu_{s}$. In the first case the efficient number of subcontractors $M$ increases, whereas in the second case it declines. The last statement follows from any first-order condition of (35) which implies that there should be less subcontractors (lower $M$ ) whenever the root firm produces more components in-house ( $n_{0}$ increases).

\section{Conclusion}

We characterized equilibrium and efficient modes of outsourcing by comparing nested with horizontal outsourcing. Nested outsourcing was generally found to be inefficient unless the cost of monitoring outsourced production lines increases sharply with the number of subcontractors, and not only with the number of outsourced components. The paper identified a market failure with nested outsourcing as the market outcome even though horizontal outsourcing is the efficient outsourcing mode. Such a market failure was found to occur at an intermediate range of the monitoring costs associated with outsourcing to multiple subcontractors.

The model and the characterization of the efficient mode of outsourcing are general insofar as we imposed no assumptions on the relative bargaining powers between the final good producer and the subcontractors. Initially, we focused on a framework where each subcontractor charges an exogenously given price for each component supplied to the producer of the final good. The advantage of such an approach is that we were able to avoid specifying the precise mechanism for how component prices are determined. Subsequently we extended the analysis to also capture a configuration where the price of the outsourced components is endogenously determined. This was carried out by characterizing the competitive market-clearing price of outsourced components under nested

(vertical) and horizontal outsourcing. Such an analysis fits particularly well in industries in 
which the brand-producing firms sell products consisting of a large number of standardized components. Finally, our analysis could be extended by investigating how the mode of outsourcing might be influenced by the final good producer's degree of bargaining power relative to component-producing firms. Interesting bargaining aspects of outsourcing have recently been studied by Fontenay and Gans (2008).

\section{References}

Cachon, G., and P. Harker. 2002. "Competition and Outsourcing with Scale Economies." Management Science 48: 1314-1333.

Fershtman C., and E. Kalai. 1993. "Complexity Considerations and Market Behavior." RAND Journal of Economics 24: 224-235.

Fontenay, C., and J. Gans. 2008. "A Bargaining Perspective on Strategic Outsourcing and Supply Competition." Strategic Management Journal 28: 819-839.

Grossman, S., and O. Hart. 1986. "The Costs and Benefits of Ownership: A Theory of Vertical and Lateral Integration." Journal of Political Economy 94: 691-719.

Grossman, G., and E. Helpman. 2002. "Integration versus Outsourcing in Industry Equilibrium." Quarterly Journal of Economics 117: 85-120.

Holmström, B., and J. Roberts. 1998. "The Boundaries of the Firm Revisited." Journal of Economic Perspectives 12: 73-94.

Kamien, M., L. Li, and D. Samet. 1989. "Bertrand Competition with Subcontracting." RAND Journal of Economics 20: 553-567.

Shy, O., and R. Stenbacka. 2003. "Strategic Outsourcing." Journal of Economic Behavior \& Organization 50: 203-224.

Shy, O., and R. Stenbacka. 2005. "Partial Outsourcing, Monitoring Cost, and Market Structure." Canadian Journal of Economics 38: 1173-1190.

Spiegel, Y. 1993. "Horizontal Subcontracting." RAND Journal of Economics 24: 570590.

Williamson, O. 1985. The Economic Institutions of Capitalism. New York: Free Press. 